\title{
La participación indígena en el abasto de la villa de Zamora, 1792
}

\author{
Jorge Silva Riquer* \\ INSTTTUTO MORA
}

INTRODUCCIÓN

$\mathbf{L}$

a intendencia de Valladolid de Michoacán ubicada en el occidente de Nueva España (ver mapa 1), ocupó un lugar medio en el concierto económico colonial a partir de su producción agropecuaria, comercial y ma. nufacturera, sólo atrás de México, Guanajuato, Puebla y Guadalajara; posición nada despreciable. Fue además el lugar

- El presente trabajo se realizó gracias al apoyo financiero de CONACYT. La parte de la captura de los registros la realizó Jesús López y el apoyo de cómputo fue de Alberto Cruzado.

Una primera versión fue presentada en el Coloquio Internacional "Historia, Cultura e Identidad Latinoamericana", Lima, Perú, septiembre de 1993. de asiento de la cultura tarasca prehispánica, de una gran trascendencia, y posteriormente de una presencia española temprana, lo que provocó un desarrollo particular en esta región. Uno de los aspectos económicos que tuvieron una importancia sobresaliente en este espacio, y que abordaremos en este trabajo, fue el comercial.

La actividad del comercio fue una práctica permanente y de cierta intensidad a lo largo del periodo colonial; las constantes referencias que nos legaron los viajeros y los agudos participantes nos lo señalan. ${ }^{1}$ Sin embargo, no conta-

${ }^{1}$ Sólo mencionaremos algunos de los trabajos que proporcionan abundante información: López Lara, El obispado, 1973; Escobar, Americana Thebatda, 1970; Ajofrín, Diario del viaje, 1936; Basalenque, Historia de la provincia, 1963; Bra- 


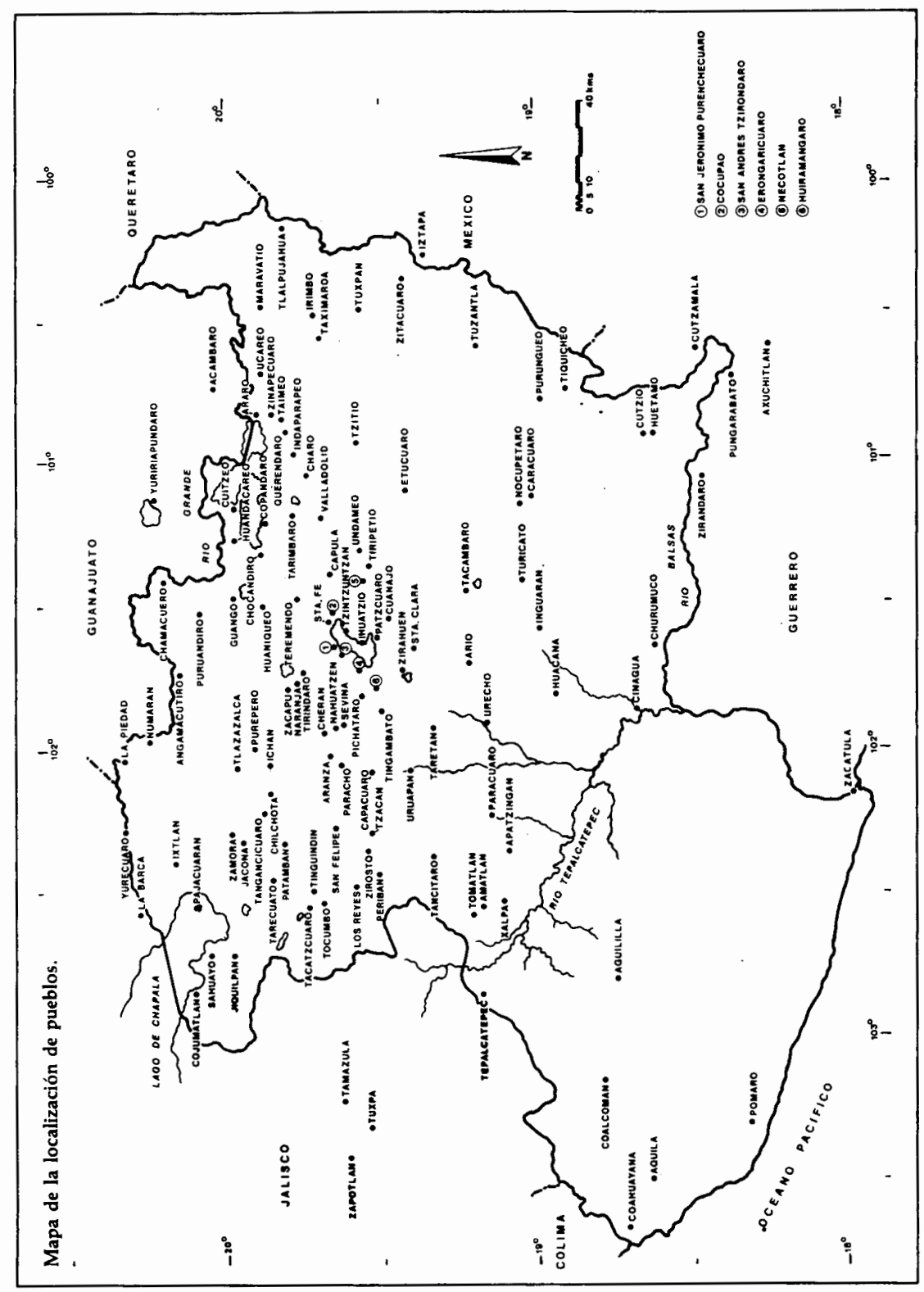


mos con registros seriados y continuos para analizar esta actividad desde el siglo XVI hasta mediados del XVIII, sólo podemos recurrir a los registros notariales que nos permiten conocer las condiciones en que se llevaron a cabo las compañías comerciales.

Es sólo hasta 1776, como parte de las reformas borbónicas, que se suspendió el arrendamiento y encabezonamiento de las rentas de alcabalas a particulares e instituciones y que podemos contar con registros diarios, mensuales y anuales de la actividad mercantil. ${ }^{2}$ Para tal efecto se creó la Dirección General de Alcabalas y Pulques de Nueva España, dividiendo a ésta en doce administraciones foráneas, con receptorías y subreceptorías, y estableciendo los medios necesarios para realizar el cobro directo. ${ }^{3}$ Una de estas admi-

vo Ugarte, Inspección ocular, 1960; Breve descripción, 1940; Casillas, Colección, 1776; Gómez de Orozco, Crónicas, 1954; Martínez de Iejarza, Análisis estadístico, 1974; Florescano y Gil, Descripciones económicas, 1973-1976, vols. I y II Acuña, Relaciones geográficas, 1987, vol. 9; Mazín Gómez, El gran Michoacán, 1986, y Ro. mero, Noticias, 1862.

2 El cobro de la alcabala se estableció desde el mismo siglo xvı, como parte de las rentas reales, sin embargo, dada la extensión, la falta de funcionarios, el alto costo administrativo y quizá el poco interés de los administradores, se procedió a arrendar y a encabezonar las rentas en particulares e instituciones, por lo que no contamos con datos entre el siglo xvı y las primeras siete décadas del XVIII para conocer el sistema que rigió en la ciudad de México. Véase Silva Herzog (comp.), Documentos, 1945, vol. Iv. A partir de 1777 contamos con series casi diarias de los ingresos por este concepto en cada receptoría en que se dividió a Nueva España, véase Garavaglia y Grosso, Las alcabalas, 1987, Silva Riquer, Las alcabalas, 1993.

3 Para una explicación más completa de la nistraciones fue la de Valladolid de $\mathrm{Mi}$ choacán, que tuvo dos momentos de organización en su interior; el prime. ro, de 1776 a 1783 , cuando se establecieron cinco receptorías principales, y un segundo a partir de 1784 , cuando se separaron de Zamora cuatro receptorías y de Zitácuaro una , quedando dividida toda la administración michoacana en diez receptorías principales. ${ }^{4}$

Más adelante, y una vez instaurado el sistema de intendencias y aplicadas las reformas, el segundo conde de Revillagigedo mandó cobrar por única vez la introducción de mercaderías de los indigenas para el año de 1792. Hasta esa fecha, y posteriormente, la comunidad india estuvo exenta del cobro de este impuesto; sin embargo los administradores reformistas, en su afán por obtener mayores ingresos para las deficitarias arcas reales, buscaron extraer la mayor cantidad de dinero de sus coIonias. ${ }^{5}$ Gracias a este hecho casi úni-

división administrativa fiscal de Nueva España véase Garavaglia y Grosso, Las alcabalas, 1987 . pp. $209-226$

${ }^{4}$ Archivo General de la Nación, Historia, vol. 600, 1793; Garavaglia y Grosso, Las alcabalas, 1987 , pp. 222-224, y Silva Riquer, Las alcabalas, 1993, pp. 20-29. Las primeras cinco receptorías principales fueron: 1) Valladolid, 2) Zamora, 3) Tlalpujahua, 4) Zitácuaro y 5) Pátzcuaro. De Zamora se desprendieron, entre 1784 y 1785, cuatro receptorías, Jiquilpan, Huetamo, Apatzingán y Ario; las tres últimas conformaron lo que se conoce como la región de la "media luna" o tierra caliente. Se ubicaron en la parte meridional de la administración alcabalatoria de Michoacán, en la costa sur del Pacífico. Y de Zitácuaro se separó la de Maravatío hasta 1806.

5 Desde el establecimiento del impuesto de alcabala se marcó una serie de exenciones a varias comunidades, entre ellas a la indigena y a los eclesiásticos, además de que se fomentaron por esta vía algunas actividades productivas como la 
co, podemos contar hoy con un registro de las mercancías que comerciaban los indigenas en los mercados urbanos. ${ }^{6}$

El presente trabajo abordará la participación indígena en el mercado urbano de Zamora en 1792 en los siguientes apartados: en el primero se hace una descripción de la ciénega y de la villa de Zamora a partir de los elementos geográficos y humanos, buscando explicar algunos de los problemas de la composición étnica y social. En el segundo presentamos el análisis de la actividad comercial, donde nos interesa señalar la participación y tendencias de estas actividades en el concierto regional de Michoacán y particularmente de Zamora. Por último, el análisis de 1792 en dos momentos, composición mercantil indígena y los valores y porcentajes de las mercancías.

\section{ZAMORA, SU ENTORNO Y SUS ACTORES}

La villa de Zamora fue fundada en 1574 , se ubicó en la parte noreste del obispa-

minería y la agricultura, y en algunos casos se protegió a ciertos grupos marginados como a las viudas, huérfanos y ancianos. Véase Fonseca y Urrutia, Htstortageneral, 1849, tomo II, pp. 5-26, y Garavaglia y Grosso, Las alcabalas, 1987, pp. 18-27. Sobre el problema de extracción de plata se puede consultar: Gamer, "Exportaciones", 1982; Klein, "La economía", 1986, y TePaske, "La crisis", 1991.

6 Ya se ha realizado un primer análisis de la participación indigena en el mercado de Tepeaca, Puebla, véase Garavaglia y Grosso, "Marchands", 1989, pp. 553-580. Este sería el segundo ejercicio al respecto, la razón está en que no se han localizado más libros con estas características; para el caso de Michoacán se puede afirmar que sólo existe el libro de Zamora. do de Michoacán (actualmente en el estado del mismo nombre). Ocupa la parte sur de la laguna de Chapala y colindó con la audiencia de la Nueva Galicia (hoy estado de Jalisco). Desde su fundación se convirtió en un lugar de paso obligado para las recuas de mulas que realizaban el intercambio de mercancías y para los pasajeros entre el centro de Nueva España y Guadalajara. ${ }^{7}$

Zamora se asentó en terrenos de ciénegas y de pantanos de la parte sur de la laguna de Chapala, ubicados a una altura de 1600 metros sobre el nivel del mar, mismos que fueron desecados por la tecnología agrícola convirtiéndolos en fértiles tierras para el cultivo. Las características del valle zamorano son muy similares a las del valle de México, las aguas tienen poco escurrimiento y la tierra está asentada en un sistema acuático subterráneo. Este valle está rodeado al norte por los cerros llamados Encinal, Atacheoy Tácari, cu. yas cumbres sobrepasan los 2000 metros de altura; al poniente, por los montes Jaceño y Platanar, con una altura menor; al sur se encuentran unas lomas y el cerro llamado Tamándaro, y al oriente la montaña llamada la Beata, con un altura de 2700 metros, y la Beatilla con 2000 metros. $^{8}$

Las descripciones de este valle desde el mismo siglo xvi hasta la actualidad lo describen así: "Es hoy una planicie amena, llanura paradisíaca, ancho valle, tiesto de flores, vergel, jardín, vega florida, espléndido plantón,

${ }^{7}$ Colinda con el pueblo de Ixtlán y Ecuandu. reo por el norte; con Churintzio por el oeste, y con Tangancícuaro y Jacona por el sur, González, Zamora, 1984, p. 19.

8 Ibid., p. 21. 


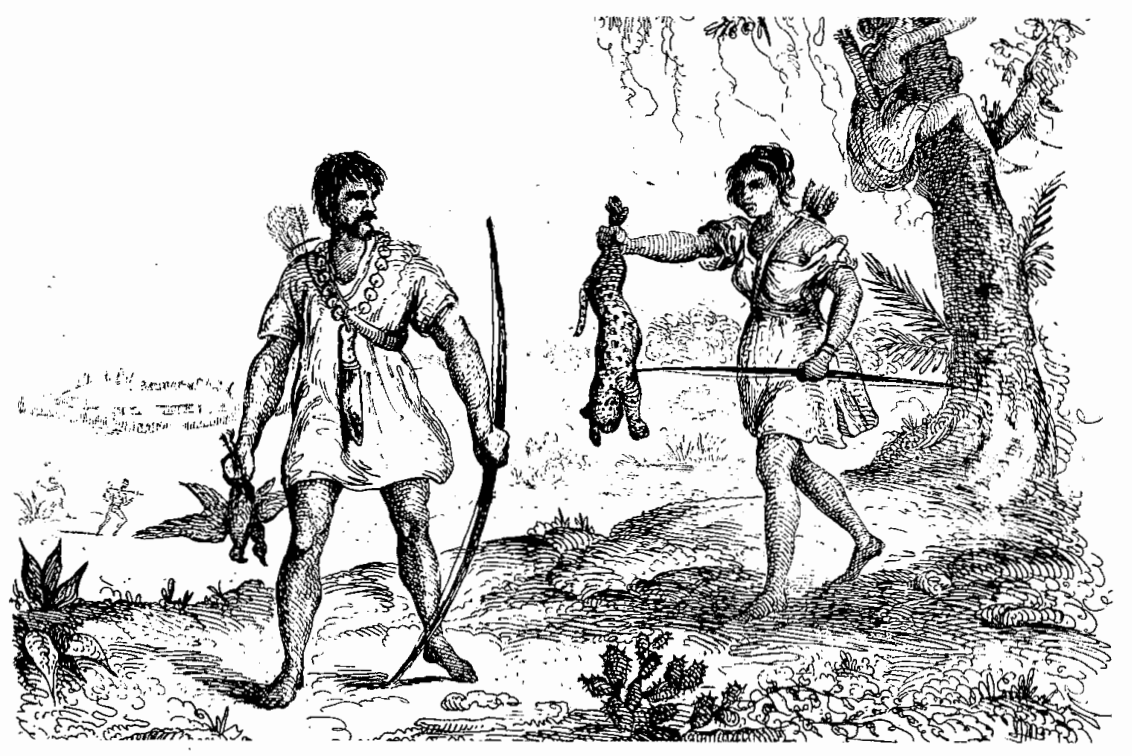

'valle ubérrimo', valdeaguas, nava tricolor, haz de verdura, 'valle de fértil entraña', 'dulce tierra', 'dulce de miel y de azúcar', recinto luminoso", siendo éstos algunos de los adjetivos utilizados. El valle ha estado irrigado por la cuenca del río Lerma, principalmente por los ríos Duero, del Naranjo, de la Alberca, del Estanque, del Pedregal, de los Baños, de la Corona, del Cupátziro, del Junguarán y del Camécuaro entre otros más. 9

La villa zamorana estuvo integrada hacia mediados del siglo XvIII por un pueblo llamado Jacona y doce rancherías, donde se asentaron alrededor de 5000 habitantes de todas las clases, tanto en la misma villa como en su jurisdición. Entre 1758 y 1761 se mandó

9 Ibid., p. 22. realizar por orden del virrey y del obispo un informe sobre el número de curatos y provincias en que estaba dividida Nueva España; de los informes recibidos nos permitimos transcribir la parte de Zamora y su pueblo de Jacona:

Que este juzgado comprende este curato y la doctrina del partido de Xacona. Que éste sólo se compone de esta villa y en ella un corto barrio de indios y algunas labores y hacienditas en su vecindario villa de Zamora, que hoy es cabecera y no tiene pueblo a ella sujeto y sólo sí un barrio de indios que llaman los tecos. El pueblo de Jacona que fue cabecera anteriormente. El pueblo de Santiago Tangamandapeo. El pueblo de los Santos Reyes de Xaripo y el pueblo de Santa Mónica de Ario, sujetos a Jacona. ${ }^{10}$

${ }^{10}$ Mazín, El gran, 1986, pp. 131-133. 
Como se aprecia en la descripción anterior, la villa zamorana tuvo corta población, tanto indígena como "blanca" o "de razón", pero se observa tam. bién que estuvo integrada por pueblos y rancherías lo que es propiamente la jurisdicción territorial; el asiento del poder judicial se mantuvo bastante lejos de este valle, casi al otro extremo de la provincia de Michoacán, en Maravatío, pueblo ubicado en el camino del occidente a la ciudad de México, colindante con la provincia de México y en el centro minero más importante de los michoacanos. A pesar de su participación comercial y agrícola, Zamora no logró tener autoridad sino hasta la implantación de los reformas borbónicas, en que se convirtió en subdelegación. ${ }^{11}$

La caída de la población indigena de fines del siglo XVI, generada a partir de las epidemias, guerras y explotación, afectó de igual manera al valle de Zamo$\mathrm{ra}, \mathrm{y}$ no es sino hasta mediados del XVII cuando se inicia la recuperación, misma que no se detiene hasta ya entrado el siglo XIX. A partir del análisis de los libros de bautismos de los habitantes de Zamora, se puede decir que la composición de la población hacia mediados del siglo XVII era de $52 \%$ de población "que se decía española" y sólo $28 \%$ de in dígena. ${ }^{12}$

Para mediados del siglo XVIII se calcula que la población indígena invirtió el porcentaje del siglo anterior, cuando representó casi $54 \%$ del total, aunque no se ubicó en la villa (ver cuadro 1 ).

11 Rees, El despotismo, 1979, pp. 97-108.

12 El porcentaje fue realizado, a partir de los registros del libro primero de bautismos de 1645-1654 de la parroquia de Zamora, por Calvo, "Migraciones", 1988, p. 213.
Sobre el crecimiento de la población hay por lo menos dos versiones que no se contradicen, pero con valores muy distintos; la primera señala que pasó de los 5000 habitantes en 1750 a 14700 hacia principios del siglo XIX, lo que representó un crecimiento de 34\%; en tan sólo 50 años se triplicó la población, ${ }^{13}$ y la segunda, donde se calcula que la población tuvo un crecimiento de $12 \%$ entre 1795 y 1823 , indicando que la guerra de Independencia no tuvo, por lo menos en Zamora, el efecto devastador que se ha señalado. ${ }^{14}$

Como se aprecia, los porcentajes de crecimiento de la población no son excluyentes, y mucho menos contradictorios; el primero cubre la segunda mitad del siglo XVII y el segundo aproximadamente 28 años, o sea la mitad de años con respecto al periodo anterior. Estos resultados señalan un comportamiento casi único en el crecimiento de la población en Michoacán; el alza registrada en Zamora sólo es comparable con el aumento dado en el pueblo de Puruándiro. El caso de la población de Valladolid, capital de la intendencia, del obispado y la más importante en la actividad comercial, tuvo un movimiento más moderado, sólo logró duplicar su número en el mismo periodo ${ }^{15}$.

13 González, Zamora, 1984, pp. 59.60; Humboltd, Ensayo, 1978 , pp. 162-167, y Morin, $M i$ choacán, 1979, pp. 64 y 87. Y para la población indígena, López, "La población", 1993 (publicado originalmente en 1963), pp. 516-530.

14 Calvo, "Migraciones", 1988, p. 214. A pesar de no proporcionar datos sobre el número de habitantes de la villa de Zamora, sus cálculos están basados en los registros de bautizos, matrimonios y defunciones del archivo parroquial de $\mathrm{Za}$ mora, que indican el crecimiento de la población.

${ }^{15}$ Haciendo el cálculo estadístico de la regre- 
El crecimiento de la población tiene dos explicaciones: la primera responde a un aumento natural de los habitantes, sin duda las condiciones permitieron éste aun a pesar del movimiento armado de independencia; la segunda poco analizada, es el problema de las migraciones; el movimiento de los grupos humanos por Michoacán en particular es una explicación necesaria de este comportamiento; veamos primero el aumento natural de la población.

Los pocos datos con que contamos para tener alguna idea del número de habitantes son bastante aleatorios (véase cuadro 1), sin embargo nos permiten hacer los siguientes cálculos para conocer la posible tendencia de crecimiento natural en un cierto periodo. ${ }^{16}$ Los datos señalan que la villa de Zamora pasó de 2300 habitantes en 1750 a 10000 en 1800 , aproximada. mente, lo que daría una tasa de crecimiento promedio anual de $2.4 \%$. Promedio grande con respecto a los registrados para toda la intendencia de Michoacán, la que registró una tasa de crecimiento de $1.2 \%$ entre los años de 1760 y 1810. Zamora representó en 1760 sólo el $0.8 \%$ de la población total registrada en todo el obispado de Michoacán, mientras que para 1800 el porcentaje

sión lineal obtenemos la tasa de crecimiento promedio anual para el caso de la villa; ésta fue de 2.4\%, con una $\mathrm{r}^{2}$ de $0.97 \mathrm{y}$ un Vt de 8.11 ; véase Floud, Métodos, 1983, pp. 178-184, y Blalock, Estadistica, 1986, pp. 377.446.

16 Para hacerlo aplicamos el método estadis. tico de la regresión lineal, la que nos permite realizar algunas comprobaciones sobre la confiabilidad de los datos y nos proporciona resultados de tendencia sobre el movimiento de éstos; véa. se Floud, Métodos, 1983, pp. 178-184, y Blalock, Estadística, 1986, pp. 377-446. fue de 1.25 , lo que nos habla de una villa con poca población en términos absolutos pero con una dinámica interna muy vigorosa, como veremos a continuación. ${ }^{17}$

Estos resultados nos permiten primero constatar, con los que nos proporciona Thomas Calvo, que a su vez los obtuvo de los libros parroquiales de Zamora, que éstos son confiables, y se. gundo, que están señalando un crecimiento natural según la tendencia obtenida, en têrminos al parecer muy cercanos a la realidad zamorana.

La composición de la población asentada fue determinada por la variedad de grupos sociales, donde la población indígena representó la parte sustancial, casi el $50 \%$, triplicando su número a lo largo del siglo xvin; más en el pueblo de Jacona, que tuvo un coeficiente de crecimiento de 1.57. Mientras que el grupo de los mulatos adquirió una mayor presencia hacia fines del siglo, cuando llegaron a ser $59 \%$ de la población asentada en los mismos pueblos. El resto de la población mantuvo una tasa de crecimiento sostenida, donde la población blanca y mestiza agrupó casi a la mitad en el último tercio del siglo XVIII. ${ }^{18}$

\footnotetext{
${ }^{17}$ Los resultados de la serie de Zamora son $\mathrm{r}^{2}$ del 0.970 significativa a $1, y$ el Vt de 8,11 . Las tasas de crecimiento promedio anual que se obtienen para todo el siglo xvII son, para la intendencia de Michoacán, de $1.5 \%$, y para Nueva España de 1.3\%, Silva Riquer, Las alcabalas, 1993, pp. 70-72; Morí, Michoacan, 1979, pp. 39-43 y 74; Cardozo, Michoacán, 1979, p. 44; Humboldt, Ensayo, 1978, pp. 167; Lerner, "Consideraciones", 1968, pp. 327-348, y Garner, "Seminario", 1992.

18 Morín, Michoacán, 1979, pp. 76-77.
} 
Los resultados anteriores son de in. terés sin duda, pero no explican por sí solos la alta tasa o los porcentajes de crecimiento, falta por incluir el otro elemento importante ya señalado, en este comportamiento, y es el problema de la migración. Los movimientos de población han sido marcados ya como parte sustancial del aumento humano en ciertos periodos. ${ }^{19}$

Primero es necesario entender el significado del proceso de migración, al que se ha definido, sin importar cuáles son las variantes que se defiendan, partiendo de que "se trata de un proceso sinérgico, es decir que, en todas sus formas funcionales, es causa y efecto de variaciones y cambios espaciales y temporales en la organización de la sociedad. La acción de migrar procede de una respuesta de comportamiento." 20

En el siglo XVIII novohispano, y michoacano, el mudarse "significó cobrar acceso a nuevos recursos, fuesen humanos o físicos; mudarse también podría significar escapar de los impuestos, de un patrón abusivo, de las responsabilidades familiares o hasta de un pasado". Esto a su vez tuvo dos condiciones, una positiva, marcada por la apertura de las fronteras agropecuarias, y una negativa, generada por la transferencia de problemas sociales, la pérdida de la cosecha o de la tierra de cultivo. ${ }^{21}$

19 Para Michoacán se han realizado algunas investigaciones sobre este problema, principalmente por David J. Robinson, quien ha publicado varios trabajos sobre la población y sus movimientos, principalmente "Patrones", 1988, pp. 169-205, donde trata de establecer patrones de migración en Michoacán en el siglo xvm.

${ }^{20}$ Robinson, "Patrones", 1988, p. 170 y nota 3.

21 Ibid., pp. 169-170 y 184-185.
Así, se puede apreciar en este siglo la existencia de dos tipos de movimientos de población, uno en la primera mitad del siglo entre subregiones, generado a partir del crecimiento económico en la agricultura y la manufactura, en los centros urbanos nucleados del Bajío; y el otro a partir de la segunda mitad del siglo, marcado por la apertura de las fronteras de la tierra caliente, "Esta migración hacia el sur y el crecimiento poblacional pueden ser contrastados con la constante disminución y reducción de centros poblados en la zona norte." 22

En el caso de Zamora observamos el siguiente comportamiento: entre 1728 y 1739 , a partir de los registros de matrimonios, se observa que los cónyuges no zamoranos constituyeron el $22.5 \%$ de los contrayentes, mientras que para el periodo de 1821-1824 fue el 31\%. La composición de la población migrante en el primer periodo estuvo integrada por los grupos étnicos superiores, de blancos a mestizos, o sea que fue el $49 \%$ del total, mientras que para las primeras décadas del siglo XIX fue de sólo el $38 \% .{ }^{23}$ Sin embargo, el movimiento migratorio fue un proceso más lento si lo comparamos con la zona de Guadalajara.

El radio de atracción de Zamora fue más lejano hacia mediados del siglo XVIII; para 1750 sólo $30 \%$ de los migrantes provenía de las haciendas y ranchos ubicadas dentro de la jurisdicción de la villa, podríamos decir que fue un movimiento intraparroquial, mientras que para 1821-1823 el proceso se in-

\footnotetext{
22 Morín, Michoacán, 1979, pp. 60-91.

${ }^{23}$ Calvo, "Migraciones", 1988, p. 216.
} 
virtió, sólo $20 \%$ de migrantes provino de fuera de los límites de la traza de la villa; el movimiento se dio dentro de la parroquia. Las posibles causas de esta modificación serian, la inseguridad por la guerra de Independencia, primero, y por el bandidaje, después. ${ }^{24}$

El primer origen de los migrantes es el obispado de Michoacán, con menor participación de México y sus alrededores; misma situación representó Guadalajara. Respecto a los caminos que sirvieron para la migración, fueron los mismos que se utilizaron para la comunicación y el comercio, el de Tierra Adentro, México, Querétaro, Celaya, León, Aguascalientes, Jerez y Zacatecas, con su transversal por Irapuato, Pénjamo y la Piedad; el camino de México a Guadalajara por la Barca, Chilchota, Valladolid, Taximaroa, Zinacantepec, y la vía de Tierra Caliente, hacia el sur. Rutas que no se modificaron, aun a pesar de la guerra de inde. pendencia. ${ }^{25}$

\section{LA ACTIVIDAD COMERCIAL ZAMOR ANA EN EL CONCIERTO REGIONAL Y EN LA VILLA, 1781-1807}

La administración de Michoacán ocupó el séptimo lugar de los valores comerciados entre 1778 y 1809 . Lugar sin duda respetable si consideramos que antes se ubicaron las administraciones de Guadalajara, Puebla, México (sin la ciudad de México), Guanajuato y San Luis Potosí, mientras que Veracruz

${ }^{24}$ Ibid., p. 216.

25 Ibid., pp. 217.218. (sin el puerto) y Michoacán están muy cercanas en cuanto al valor total. Respecto al porcentaje que éstas tuvieron, los resultados señalan otro sentido, fue la región del occidente, integrada por Guadalajara y Michoacán, la que representó el $23 \%$ del monto total comerciado. ${ }^{26}$

Respecto a la participación por administraciones, la mayorcantidad se la llevó Guadalajara, con $90 \%$, mientras que la de Michoacán sólo participó con $10 \%$ de la parte proporcional de la región occidental. Pero el crecimiento en cuanto a los valores y a las tasas de crecimiento, la administración michoacana presentó características importantes de señalar. ${ }^{27}$

La administración michoacana de alcabalas se puede dividir a su vez en cuatro regiones, que hemos denominado como el centro, con las receptorías de Valladolid (la ciudad de Morelia) y Pátzcuaro; el oriente con Zitácuaro, Maravatío y Tlalpujahua; la tierra caliente con Ario, Huetamo y Apatzingán, y por último la ciénega, integrada por Zamora y Jiquilpan. Esta última participó con $27.5 \%$ del valor total, sólo atrás de la región del centro, que

${ }^{26}$ Garavaglia y Grosso, "De Veracruz", 1987, pp. 11-13 y 43. Las regiones las integraron con las siguientes administraciones alcabalatorias: el occidente con Guadalajara y Michoacán; el centro, con Guanajuato y México, con 23\%; el norte con Sonora, Durango, San Luis Potosí y Zacatecas, con 24\%; el oriente con Puebla y Veracruz, con 22\%; y el sur con Oaxaca y Tabasco, con Yucatán, con $7 \%$.

${ }^{27}$ Garavaglia y Grosso, "De Veracruz", 1987, pp. 13-15, donde señalan la existencia de un mayor dinamismo comercial en las regiones del norte y occidente y, dentro de esta última, la de Michoacán en particular, razón por la cual no abundaré más en su análisis. 


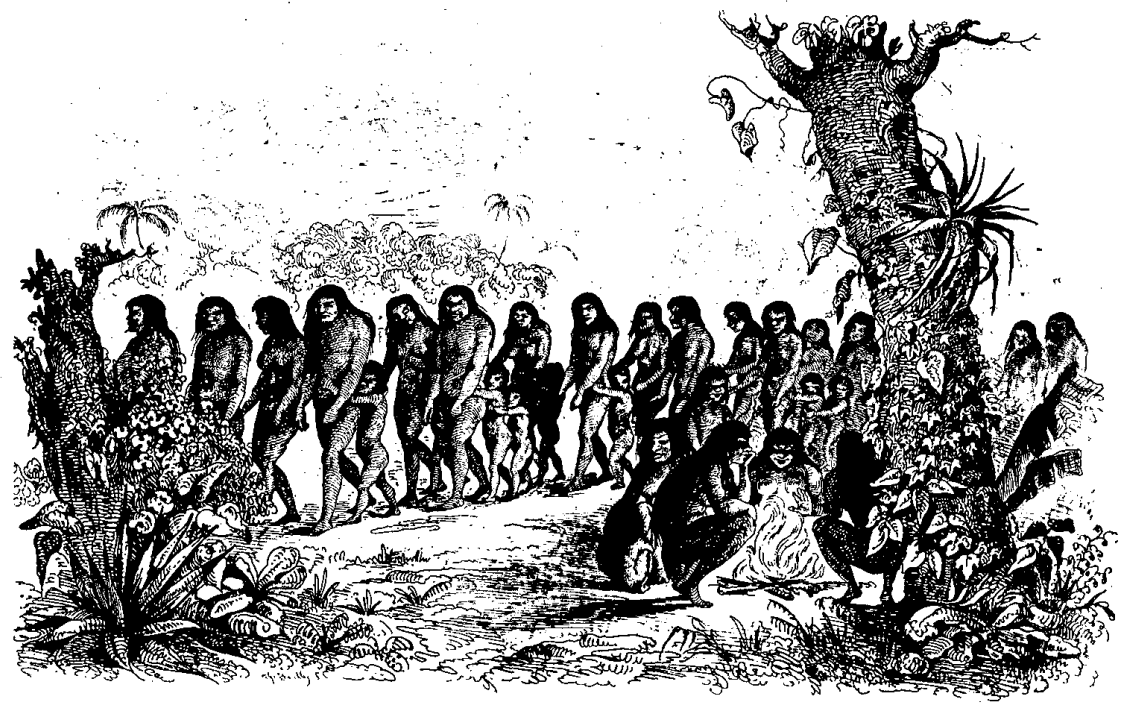

ocupó $48 \%$ del valor comercial. Pero en el interior, el suelo alcabalatorio de Zamora representó $23.6 \%$, mientras que Jiquilpan sólo $3.9 \%$ con respecto al total. En este sentido, y a partir de los anteriores datos, los suelos alcabalatorios que ocuparon más de $50 \%$ del valor total comercial entre 1778 y 1809 , fueron Valladolid con $33.4 \%$ y Zamora con 23.6 por ciento. ${ }^{28}$

De lo anterior nos interesa rescatar los valores comerciales registrados entre 1781 y 1807 , periodo que nos permite centrar en su justa medida los valores comerciados por cada ramo re-

28 Silva Riquer, Las alcabalas, 1993, pp. 110 , en este artículo se realizó un análisis de los montos comerciados por cada región para conocer su comportamiemto y participación. caudado antes y después del año de 1792 , cuando se determinó cobrar a los productos introducidos por los indígenas en Zamora. El análisis lo realizaré en dos niveles; el primero, de toda la jurisdicción alcabalatoria de Zamora, esto es, con las receptorías, subreceptorías y pueblos sujetos; el segundo será sólo de la villa de Zamora, situación que permitirá centrar los valores comerciales de los indigenas en términos confiables. 29

29 Antes de continuar es necesario hacer la siguiente acotación aclaratoria; el suelo fiscal de Zamora, incluidas las cuatro receptorías, abarcó un espacio muy amplio, por lo que los receptores determinaron establecer con la anuencia de la Dirección General de Alcabalas el sistema de cobro indirecto. Este consistió en establecer convenios entre los introductores y el receptor 
Cuadro 1. Población no indígena e indígena asentada en la villa y jurisdicción de Zamora, 1743-1800

\begin{tabular}{|c|c|c|c|c|c|c|c|}
\hline Años & $\begin{array}{l}\text { Población } \\
\text { o. de Mich. }\end{array}$ & $\begin{array}{c}\% \\
\text { respecto } \\
\text { a la villa }\end{array}$ & $\begin{array}{c}\text { Población } \\
\text { de la villa }\end{array}$ & $\begin{array}{l}\quad \% \\
\text { respecto } \\
\text { al total } \\
\text { poraño }\end{array}$ & $\begin{array}{c}\text { Población } \\
\text { india }\end{array}$ & $\begin{array}{l}\quad \% \\
\text { respecto } \\
\text { al total } \\
\text { poraño }\end{array}$ & $\begin{array}{c}\text { Total } \\
\text { poraño }\end{array}$ \\
\hline $\begin{array}{l}1743 \\
1750 \\
1760\end{array}$ & 430868 & 0.79 & $\begin{array}{l}1943 \\
2300 \\
3400 \\
6000\end{array}$ & 45.95 & 2705 & 54.05 & $\begin{array}{l}1943 \\
5005 \\
3400 \\
6000\end{array}$ \\
\hline $30 x$ & 800000 & 1.25 & 10000 & 68.00 & 4706 & 32.00 & 14706 \\
\hline
\end{tabular}

Fuente: a Humboldt, 1978, pp. 162-167 y Morin, 1979, pp. 64-87.

b González, 1984, pp. 59-60; Humboldt, 1978, pp. 162-167; Morin, 1979, pp. 64-87.

c López, 1963, pp. 516-530.

Cuadro 2. Valores comerciales por ramo de la jurisdicción de Zamora, 1781-1807 (pesos)

$\begin{array}{lccccc}\text { Años } & \begin{array}{c}\text { Total del } \\ \text { viento }\end{array} & \begin{array}{c}\text { \%respecto } \\ \text { al total } \\ \text { poraño }\end{array} & \begin{array}{c}\text { Total de } \\ \text { igualas }\end{array} & \begin{array}{c}\text { \%respecto } \\ \text { al total } \\ \text { poraño }\end{array} & \begin{array}{c}\text { Total } \\ \text { poraño }\end{array} \\ 1781 & 47113 & 18.40 & 208963 & 81.60 & 256075 \\ 1785 & 49650 & 14.12 & 302088 & 85.88 & 351738 \\ 1790 & 53783 & 14.81 & 309400 & 85.19 & 363183 \\ 1792 & 132658 & 33.92 & 258417 & 66.08 & 391075 \\ 1793 & 91233 & 23.60 & 295350 & 76.40 & 386583 \\ 1794 & 88450 & 20.62 & 340483 & 79.38 & 428933 \\ 1800 & 210883 & 46.32 & 244383 & 53.68 & 455267 \\ 1801 & 179767 & 40.11 & 268400 & 59.89 & 448167 \\ 1802 & 204617 & 50.45 & 200950 & 49.55 & 405567 \\ 1803 & 188100 & 50.21 & 186550 & 49.79 & 374650 \\ 1805 & 235733 & 51.96 & 217967 & 48.04 & 453700 \\ 1806 & 208567 & 51.23 & 198550 & 48.77 & 407117 \\ 1807 & 239467 & 54.26 & 201833 & 45.74 & 441300\end{array}$

Resultados del periodo 1781-1807

\begin{tabular}{lrrrrr} 
Total & 1930021 & 37.38 & 3233333 & 62.62 & \multicolumn{1}{c}{5163354} \\
Media & 156909 & & 252030.90 & & 408939.9 \\
Std & 70839.76 & & 48843.59 & & 52682.44 \\
Cv & 45.15 & & 19.38 & & 12.88
\end{tabular}

Fuente: AGN, AFAPM, Zamora, Libros de la Administración Real de Alcabalas, 1781-1807. 
Antes de continuar me interesa señalar cómo estaba integrada la jurisdic. ción de Zamora. Al igual que cualquier otra, estaba dividida en receptorías y subreceptorías; para el periodo que analizaremos a continuación hemos tomado la división a partir de 1784 , cuando se han separado ya las receptorías de Ario, Jiquilpan, Huetamo y Apatzin. gán. La villa de Zamora estaba integrada por ocho pueblos sujetos, a saber: San Bartolomé, Tangancícuaro, Santiago, Buenavista, Ixtlán, Sahuayo, Guarachita y Jacona, y por nueve subreceptorias: Atacheo, Penjamillo, Ecuandureo, Zináparo, Numarán, La Piedad, Chilchota, Yerécuaro y Tlazazalca. Para los fines del presente trabajo, cuando nos referimos a la jurisdicción de Zamora se incluyen los ocho pueblos sujetos y las nueve subreceptorías, mientras que cuando hablamos de la villa de Zamora, sólo nos referimos a los valores de ésta, sin los ocho pueblos sujetos. Y por último, los valores

de rentas para determinar, con base en sus introducciones anuales, el monto e impuesto que deberían pagar en tres pagos al año. A este sistema se le conoció como igualas, y resolvió el problema de la distancia entre la oficina y el introductor. Sin embargo ocasionó muchos problemas, contrabando, falta de declaraciones, cohechos, entre otros. Para nosotros el principal problema consiste en que los ingresos por igualas no determinan ni el ramo, ni la variedad, ni los precios de las mercancías, mucho menos el origen, problema que nos impide llevar el estudio a niveles más discriminados. Para efectos de este trabajo las igualas no tienen una incidencia fundamental, como pueden ser los valores del ramo del viento, sin embargo esto no es una razón de peso, pueden haberse ocultado en el concepto de igualas valores mucho más altos que los registrados en los libros reales. Véase Silva Riquer, Las alcabalas, 1993, pp. 7080 . que se han trabajado se refieren, como ya se dijo, a los ramos del viento ${ }^{30} \mathrm{y}$ de igualas entre 1781 y $1807 .{ }^{31}$

La tasa de crecimiento promedio anual de los valores comerciales totales para ese periodo fue de $1.5 \%$, representando por el concepto de igualas el $-1.3 \%$ y por el del viento el $7.3 \%$ (ver cuadro 2). La tendencia de los valores de cada uno de los ramos indicados es la siguiente: los valores recaudados por el viento mantienen un alza constante e importante, pasaron de 47113 pesos en 1781 a 239467 en 1807 . Mientras que los valores de las igualas mantienen una caída ligera que, a diferencia del alza del monto del viento, tiene mayor incidencia en la tendencia del valor total, que presenta un ligero crecimiento hacia fines del periodo (ver gráfica 1).

El mayor dinamismo lo representaron los valores del viento, que tuvo dos ciclos, el primero entre 1781 y 1794 , con su mejor año precisamente en 1792, y el comprendido entre 1794 y 1807 , donde no existe caída semejante a la de 1790. Las igualas son más bien descendentes, con algunos años de recuperación como $1785,1794,1801$ y 1805 , cuando se presentan valores si. milares a los primeros (ver gráfica 1). ${ }^{32}$

30 Los valores registrados en los libros del viento se refieren, para el caso de la Administración michoacana, a la introducción de la producción del entorno urbano, que no requieren de guía para su circulación, por lo que nunca se registra su origen como en los otros ramos, y los valores consignados en éstos son superiores a los 10 pesos, Silvia Garrido, "LaCiudad" (en prensa), pp. 20-21

${ }_{31}$ Silva Riquer, Las alcabalas, 1993, p. 30.

32 La media de los valores de cada uno de los ramos es: viento 156909 pesos e igualas 252 
Respecto a los valores comerciales de la villa de Zamora en el mismo pe. riodo, las tendencias fueron las siguientes: el ramo del viento presentó una tasa de crecimiento promedio anual de $6.2 \%$, mientras que para las igualas fue de $-5.3 \%$ y, para el total, de $0.2 \%$. En los comportamientos entre los valores del viento y de las igualas, mientras la primera sube, la segunda baja casi en la misma proporción, haciendo que el resultado total presente una estabilidad casi permanente (ver gráfica 2).

Aquí los valores se invierten respecto a los presentados para toda la jurisdicción alcabalatoria, donde los montos son mayores para el viento, representando el $51 \%$ del periodo, mientras que las igualas sólo el $49 \%$. Por un lado los ingresos van aumentando y por otro van en caída sostenida (ver cuadro 3). La caída más significativa de los valores del viento fue la del año de 1790 , misma que no se presenta nuevamente salvo en los años de 1793 y 1794 , en que cayó sin llegar al valor más bajo. A partir de este último año se mantiene al alza. Las igualas presentan un movimiento más inquieto, dividido en dos periodos, uno de estabilidad con ligeros crecimientos en 1790 y 1794 , y otro de caída constante con alzas en 1801 y 1805 , nunca como las anteriores.

030, una diferencia de casi el 40\%; otro valor importante es el coeficiente de variación (Cv) de los valores de la igualas: 19.38 , mucho menor que el del viento, lo que nos indica que a pesar de los problemas en los registros introductorios por medio del pago indirecto, los valores consignados por igualas son mayores que los del viento. Situación que nos habla de cierta confiabilidad en éstos, sin echar las campanas al vuelo.
El cambio en el comportamiento de los valores comerciales se dio en el pe. riodo de 1794 a 1800 , para el cual no tenemos datos y no podemos explicar nada, sólo señalar el problema. Sin em. bargo, el año que nos interesa en particular es 1792 y, como se aprecia en la gráfica 2, es un año con un registro muy cercano al promedio de todo el periodo, o sea que estamos, muy posiblemente, ante un año con carac. terísticas estables, lo que permitirá hacer más sólido el estudio del libro de indios.

\section{LA COMPOSICIÓN MERCANTIL INDIGENA DE LA VILLA DE ZAMORA EN 1792}

Como ya se mencionó, en 1792 los receptores de alcabalas aplicaron el cobro del impuesto a la circulación, a la introducción de mercancías indígenas. Para poder apreciar mejor la proporción que ocuparon estos valores en el mercado urbano de Zamora, me permito presentar antes una comparación anual de los diferentes ramos ya mencionados en el apartado anterior y el valor del año a estudiar. El periodo está comprendido entre 1790 y 1794, faltando sólo 1791, o sea que tenemos casi el $90 \%$ de la serie, aunque ésta sea muy corta.

En el periodo señalado podemos observar el siguiente comportamiento, los valores del viento, salvo el año inicial, tuvieron un ingreso inferior a la media. Los valores de las igualas mantuvieron sus valores por arriba de la media, lo que significa que, por lo menos en este periodo, los receptores es- 
Cuadro 3. Valores de la villa de Zamora entre 1781 y 1807 (pesos)

$\begin{array}{lrrrrrrr}\text { Años } & \begin{array}{c}\text { Total del } \\ \text { viento }\end{array} & \begin{array}{c}\% \\ \text { respecto } \\ \text { al total } \\ \text { poraño }\end{array} & \begin{array}{r}\text { Total de } \\ \text { igualas }\end{array} & \begin{array}{r}\% \\ \text { respecto } \\ \text { altotal } \\ \text { poraño }\end{array} & \begin{array}{r}\text { Total de } \\ \text { indios }\end{array} & \begin{array}{c}\text { respecto } \\ \text { altotal } \\ \text { poraño }\end{array} & \begin{array}{r}\text { Total } \\ \text { poraño }\end{array} \\ 1781 & 38963 & 34.74 & 73200 & 65.26 & & & 112163 \\ 1785 & 28438 & 23.38 & 93188 & 76.62 & & & 121625 \\ 1790 & 10417 & 8.40 & 113550 & 91.60 & & & 123967 \\ 1792 & 73500 & 37.09 & 88017 & 44.41 & 36673 & 18.50 & 161517 \\ 1793 & 41867 & 29.34 & 100817 & 70.66 & & & 142683 \\ 1794 & 45250 & 27.76 & 117733 & 72.24 & & & 162983 \\ 1800 & 94333 & 67.17 & 46117 & 32.83 & & & 140450 \\ 1801 & 133500 & 65.74 & 69567 & 34.26 & & & 203067 \\ 1802 & 77383 & 59.61 & 52433 & 40.39 & & & 129817 \\ 1803 & 66500 & 78.95 & 17733 & 21.05 & 84233 \\ 1805 & 103183 & 69.83 & 44583 & 30.17 & & 147767 \\ 1806 & 100250 & 80.03 & 25017 & 19.97 & & 125267 \\ 1807 & 103100 & 75.15 & 34100 & 24.85 & & & 137200\end{array}$

Resultados totales del periodo 1781-1807

$\begin{array}{lcccrr}\text { Total } & 916683 & 51.13 & 876054 & 48.87 & 1792738 \\ \text { Media } & 70514.1025 & & 67388.7820 & & 137902.8 \\ \text { Std } & 34481.5817 & & 32198.7957 & & 27438.49 \\ \text { Cv } & 48.90 & & 47.78 & & 19.90\end{array}$

Fuente: AGN, AFAPM, Zamora, Libros de la Administración Real de Alcabalas, 1781-1807. 
tablecieron igualas más altas con los introductores, ¿por una mejor negociación?, ¿debido a un mejor control?, ¿se rompió la posible negociación externa para cobrar menos a los comerciantes que gratificaran esta prebenda?, pueden ser algunas de las preguntas que se formularian y que esperarán una respuesta a futuro.

Así, salvo el valor del viento de 1790 , todos los demás mantienen una constante; al incluir el valor de la recaudación indígena observamos un hecho importante que consiste en un comportamiento casi igual de los valores en los mismos niveles. Los montos se mantienen en la misma proporción, y cuando se integran los valores cobrados a los indios la proporción no cambia. A pesar de que sólo contamos con un año de estos ingresos, la proporción mantenida en los cinco años referidos entre los montos del viento y de igualas nos permite, primero, confirmar el planteamiento de que el año elegido presenta características constantes en un periodo; segundo, que a pesar de la introducción de los indios, los valores no sufren alteraciones, salvo las igualas que aumentan, pero recordemos las observaciones hechas antes como se aprecia en 1793 y 1794 (ver gráfica 3).

Si comparamos los montos de cada uno de los rubros que se contemplan, podemos ver que las igualas, como era de esperarse, representaron el mayor valor con 88017 pesos, el viento ocupó el segundo lugar con 73500 pesos, mientras que los ingresos mercantiles indígenas sólo fueron de 36673 pesos (ver cuadro 3). Si estos valores los representamos gráficamente, podemos observar que el primer rubro repre. sentó $44 \%$, el segundo $37 \%$ y la participación indígena el nada despreciable $18 \%$ (ver gráfica 4).

Esto puede tener varias explicaciones, una es que la participación indígena de 1792 está señalando un porcentaje bastante cercano a la realidad por el comportamiento casi constante de los otros rubros en la serie; otra fue que al enterarse de la disposición virreinal de cobrar la introducción a los indios, éstos hayan determinado no asistir al mercado, lo que debería haber repercutido en un incremento de otros rubros, como el viento por ejemplo, situación que al parecer no sucedió. Así, podemos proponer que la participación indígena en el mercado urbano zamorano tuvo una significativa y sustancial presencia, pero veamos cómo estuvo compuesta.

Se registraron un total de 1350 introductores indígenas de mercancías en todo el año, de los cuales una buena parte fueron comerciantes que asistieron más de una vez al mercado. Después de realizar las agrupaciones correspondientes podemos afirmar que sólo fueron 430 comerciantes distintos, hecho que reduce considerable. mente el espectro de éstos. Los hemos ordenado por grupos de veces registradas en el libro a lo largo de 1792, encontrando lo siguiente (ver gráfica 5): organizamos siete grupos donde presentamos a los comerciantes que asistieron al mercado cada cinco veces; así, se observa que el nivel más reducido, o sea el de una a cinco veces, es el mayoritario y ocupó el 87\% de los casos; mientras que el siguiente, el 6\%; el de once a quince veces, el $4 \%$; el de 
16 a 20 , el $2 \%$, y así sucesivamente has. ta llegar a los grupos donde los porcentajes son tan reducidos que llegan a la unidad.

Los anteriores datos quedarían fuera de contexto si no los relacionamos con los valores que introdujeron cada uno de los grupos; así, antes de cualquier especulación presentamos esta parte para dimensionar mejor el problema del abasto indígena, para lo que hemos agrupado los valores que introdujo cada comerciante en los grupos ya señalados. De esta forma la situación es muy diferente; para el caso del mayor número de veces de introduc. ción el porcentaje de valor comercial fue de $46 \% ; 12 \%$ para los dos siguientes; $9 \%$ y $6 \%$ para los dos que continúan, y $8 \%$ para el de 31 a 35 veces (ver gráfica 5).

Sin perder de vista este resultado, es indispensable señalar que en el caso de 31 a 35 veces sólo se registró a una sola persona con un total de 330 pesos, mientras que en el primero, de una a cinco veces, el rango cubrió a 373 mercaderes, con 2606 pesos, que divididos entre todos da un promedio de 7 pesos por cada uno; el grupo de 26 a 30 veces es un caso similar, en valor registraron un total de 445 pesos siendo solamente dos comerciantes, lo que da 224 pesos por cada uno, aun el siguiente grupo representó un alto valor, 665 pesos entre cinco introductores, casi 133 pesos por cada uno. Los siguientes tienen una menor participación en los valores introducidos (ver la gráfica 5).

Estamos ante una introducción indigena muy concentrada en pocos introductores que controlaban la circula- ción de ciertas mercaderías para el abasto de la villa, al parecer ante una compleja organización de comercialización de productos indígenas maneja. da sólo por algunos de ellos, que pudieron ser los caciques o bien aquellos que se habían integrado perfectamente al sistema económico colonial. Algunas de estas especulaciones se queda. rán sólo en eso, ya que no contamos con mayores datos para un periodo más largo. Sin embargo, la concentración de las mercancías es un hecho evidente e irrefutable; a pesar de ser un libro único, el control de ciertas mercancías, ya sea por el valor intrínseco, por su alta demanda al interior de la propia villa o bien en otros mercados de consumo, provocó que un grupo reducido de comerciantes indígenas controlaran, me atrevería a sugerir, desde la producción misma hasta la circulación de los productos.

A estas alturas muchos de ustedes se habrán preguntado ya, o estarán por hacerlo, de qué productos estamos hablando, cuál fue la composición mercantil; antes de seguir con las conclusiones adelantadas, hablemos sobre las mercancías, los valores y las calidades introducidas por los indígenas en 1792.

El libro registró un total de $19 \mathrm{mer}$ cancías, que hemos agrupado por orden de importancia de acuerdo con el porcentaje que representaron con respecto al valor total registrado en 1792: las mantas $58.77 \%$; la fruta $14.42 \%$; la loza $9.04 \%$; el ocote $3.27 \%$; los sombreros $3.19 \%$ en dos variedades; las vaquetas $3.16 \%$; el chile $2.46 \%$ en dos variedades; los aparejos 1.14\%; el frijol $0.93 \%$; el algodón $0.79 \%$; las mangas 
$0.58 \%$; los fustes $0.42 \%$; el arroz $0.34 \%$; el coco y el cacahuate $0.31 \%$ cada uno; la harina de trigo $0.26 \%$; los cortes $0.24 \%$; la carne de cerdo $0.21 \%, y$ los cueros 0.16 por ciento. ${ }^{33}$

Estos datos nos permiten confirmar lo mencionado anteriormente; son algunas mercaderías, las más importantes por su valor o por su demanda, las que fueron controladas por unos cuantos mercaderes indios, en este caso la manta, que representó más de la mitad del valor anual pero que estuvo acaparada en mayor medida por un solo comerciante, éste fue Martín Luciano, registrado con 32 introducciones con un total de 56 cortes; como ya se mencionó, representó un valor de 330 pesos. Pero no es el único, hay más de cinco comerciantes con características similares: Isabel López, Joaquín López, José Nieves, José Ayala, José Jerónimo. ${ }^{34}$

En los registros de la loza la situación es muy similar; aquí fue Antonio Andrés el mayor introductor con 25 cargas, todas de la provincia zamorana. El ocote representó un hecho significativo; ocupó el tercer lugar en el número de introducciones, donde Benito Santos introdujo un total de 32 cargas, Pedro Domingo 31, y Jerónimo Simón 37.35

En este caso sólo estos tres comerciantes; por mencionar a los que registraron mayor cantidad de ocote. En estos ejemplos hemos querido señalar que no hubo una gran variedad de mercaderías introducidas por los indígenas, pero además resaltar la importan-

$33 \mathrm{Ibid}$. Libro de indígenas, 1792.

34 Ibid, Libro de indios, 1792.

$35 \mathrm{Ibid}$. cia que tuvo la demanda de la misma villa; así encontramos por lo menos dos niveles, en el primero y el más inmediato es el consumo directo del producto, en este caso el ocote; el segundo está determinado por la demanda de ciertos productos elaborados, que servirán más tarde como materias primas en otros procesos; me refiero a la manta, que podía haberse tejido en los talleres domésticos de los habitantes de la villa o bien salir para su venta de otros centros. Por último, la loza podría haber cubierto las necesidades más lejanas de demandantes de este producto o bien cubrir la de la población zamorana.

Una mercancía que llama la atención dentro de este abanico es la fruta; en principio estaba exenta del pago alcabalotorio, además, por ser un producto casi siempre indigena, es muy dificil rastreario; en este ejemplo representó casi el $14.42 \%$ del valor total, sin duda un porcentaje muy alto si lo comparamos con los de otras mercaderías. Pero lo que nos interesa señalar es que a diferencia de la concentración que se dio en la manta y en el ocote, la fruta fue introducida en pequeñas cantidades por un gran número de indígenas; el que mayor cantidad de cargas registró fue Sebastián Jerónimo con doce cargas; de ahí un reducido grupo con diez cargas, y le siguen una infinidad de mercaderes con una carga. ${ }^{36}$

Esto nos permite plantear la concentración de mercancías con ciertas características, como pueden ser el valor intrínseco, la demanda y la calidad del producto, donde la existencia de comerciantes con mayor capacidad de

${ }^{36} \mathrm{Ibid}$. 
compra permitieron este acaparamiento. Al mismo tiempo, existió una buena cantidad de mercancías que, a pesar de su demanda, directa fundamentalmente, no generaron las ganancias necesarias que permitieran una alta cotización, lo que provocó una monopolización de ellas.

\section{CONCLUSIONES}

Retomemos algunas de las aseveraciones ya señaladas a lo largo del texto que nos permitan plantear mejor las conclusiones a las que llegamos en este trabajo. Primeramente, los diferentes grupos raciales que se asentaron en Zamora nos dan idea de una sociedad donde el grupo blanco tuvo una importancia mayor, a pesar de que hacia fines del siglo XviII aumentó la población in. dígena y mestiza. En donde el movimiento de la población permitió el establecimiento de una sociedad tal vez más dinámica, por lo menos en el aspecto cuantitativo, no se da aún en el aspecto de consumo y niveles de bienestar. Pero habría que empezar a cuestionarse sobre este punto.

Lo que sí podemos afirmar es que a pesar de que la población indígena se ubicó en los pueblos sujetos a la villa zamorana, ésta representó un número casi igual o mayor que el registrado para los habitantes "blancos" de la villa en el mismo año, con un crecimiento verdaderamente significativo y con una actividad comercial sustantiva en el concierto regional. Aunque no fue una de las villas con mayor población -representó apenas 1\% de todo el obis- pado-, sí tuvo un crecimiento importante y un movimiento dinámico hacia fines del periodo colonial, que estuvo vinculado a las actividades desarrolladas en el interior del valle de Zamora; más aún, como se empieza a demostrar, el comportamiento de la población no presentó movimientos depresivos a pesar del movimiento de independecia.

Respecto a los valores mercantiles comerciados, la jurisdicción de Zamora ocupó el segundo lugar dentro de las receptorías en que se dividió la administración michoacana. Su comportamiento habla de las necesidades de cubrir una serie de demandas que debía satisfacer, y en donde los valores registrados por el ramo del viento tuvieron un crecimiento sostenido a lo largo del periodo analizado. Respecto a los registros de igualas el problema queda planteado y posiblemente no pueda definirse a corto plazo, recordemos que éstas ocultan los valores y mercancías introducidas.

En el caso analizado anteriormente, observamos que la participación indígena tuvo varias características importantes de señalar. Primeramente, que representó un poco menos de la sexta parte del valor total registrado en 1792 , lo que nos permite plantear que el comercio indígena que abastecía a la villa tuvo un valor significativo respecto a los otros; en segundo término, la existencia de una concentración en la comercialización de ciertos productos, como la manta, que por su valor y demanda tenían un mercado seguro en el interior de la propia villa y en otros lugares más lejanos. Por último, las mercancías registradas por los indíge- 
nas, lejos de ser una producción muy variada, fue muy concentrada en ciertas mercaderías, algunas que fueron comercializadas por los propios indios, eran de poco monto y de control casi exclusivo de ellos, como el ocote y la fruta.

La concentración de introductores de mantas nos lleva a pensar en la existencia del tejido a domicilio; pudo ser elaborado por los propios indígenas y posteriormente acaparado y comercializado por los dueños del algodón y/o de la producción. Éstos posiblemente pagaban el proceso de hilatura a los indios, lo que les permitía posteriormente introducir este producto en la villa.

Otro hecho importante fue la existencia de un amplio espectro de otros introductores indigenas que asistían constantemente al mercado urbano, donde llevaban parte de su produc. ción o aquellos productos que obte. nían del bosque. Al mismo tiempo, en el mercado urbano cubrían algunas de sus necesidades, ya fuera en los días de tianguis o en cualquier otro día. Estos "comerciantes" fueron los más, pero representaron el valor más pequeño registrado en el año. Los menos fueron los verdaderos comerciantes, o posiblemente los prestanombres de otros que sí estaban obligados a pagar el im. puesto alcabalatorio y que por este medio lo evadían. En cualquier caso, estamos ante un mercado controlado por un grupo muy reducido de comerciantes indígenas que acaparó, al parecer, las mercancías de mayor valor intrínseco y de una demanda mucho más amplia.

No quisiera terminar este trabajo sin hacer referencia a otra investigación que se realizó para Tepeaca en la región norte del actual estado de Puebla. Parece ser que el patrón se repite, la existencia de una concentración de ciertas mercancías y valores altos en un reducido grupo; la dispersión de las demás mercaderías en una infinidad de pequeños comerciantes y la participa. ción muy similar en los valores totales, $30 \%$ en Tepeaca y casi $20 \%$ en Zamora, son algunos de los resultados en los que existe semejanza entre dos espacios muy distantes y distintos a la vez; Tepeaca es un mercado casi indígena, no así la villa de Zamora.

En los valores totales existe una diferencia importante, para Tepeaca el monto fue de 11845 pesos, mientras que para Zamora fue de 36676 pesos, elemento que no es comparable por varias razones, una de ellas es la dimensión del mercado urbano y del número de pobladores. A pesar de esto, podemos empezar a plantear la validez de esta fuente para conocer la composición mercantil, los valores y las cantidades, así como empezar a proponer una serie de conclusiones similares para diferentes espacios, propuesta que queda abierta para futuras colaboraciones. 
Gráfica 1. Tendencia de los valores comerciales, de Zamora y su jurisdicción, 1781-1807

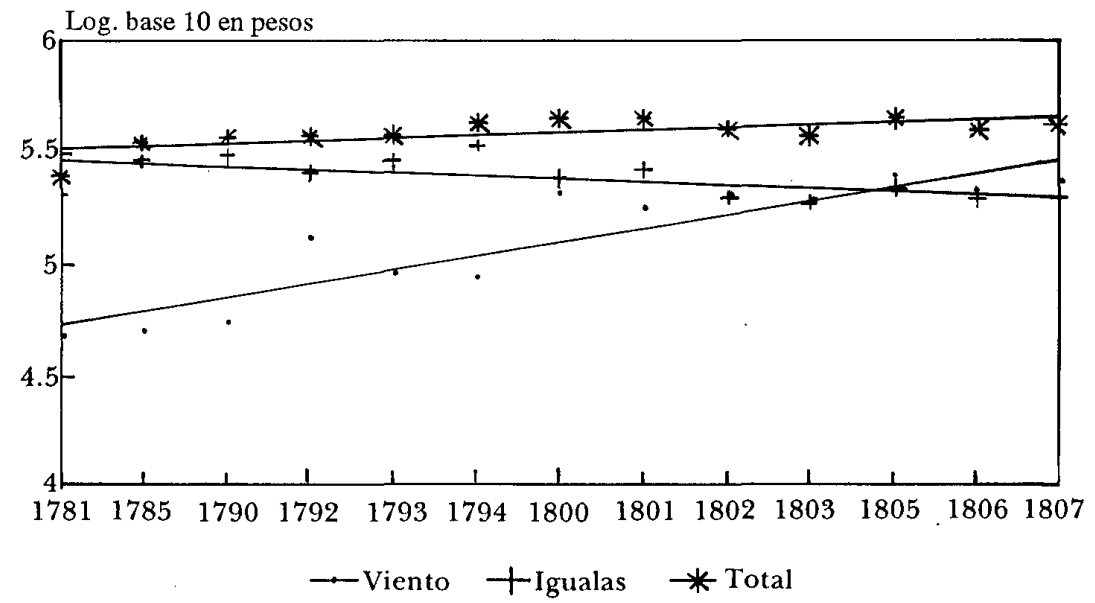

Gráfica 2. Tendencia de los valores comerciales, de la villa de Zamora, 1781-1807

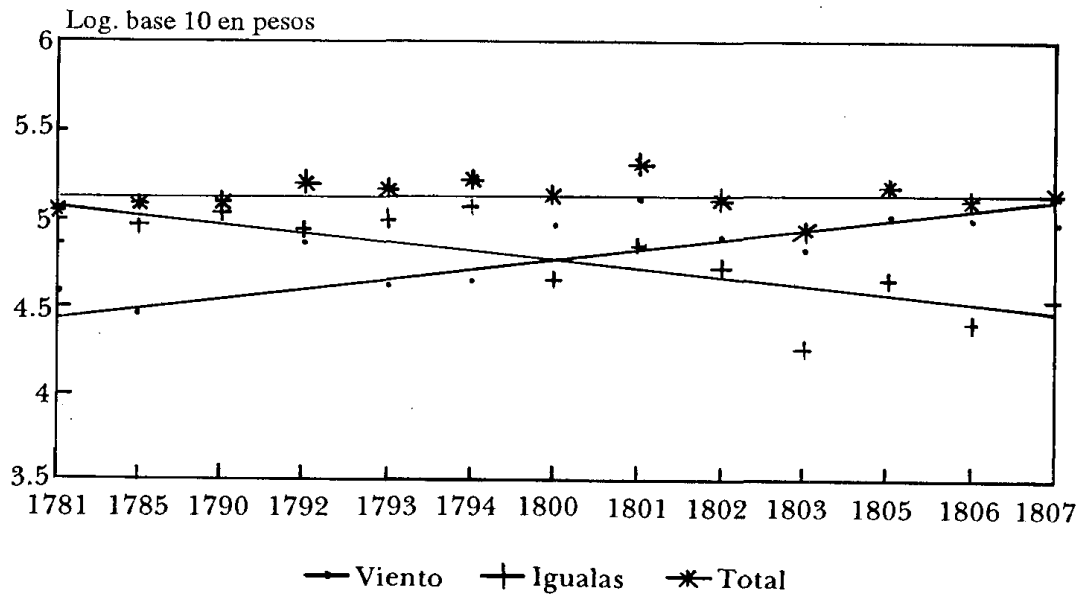

Fuente: AGN, AFAPM, Zamora, Libros de la Administración Real, 1781-1807 


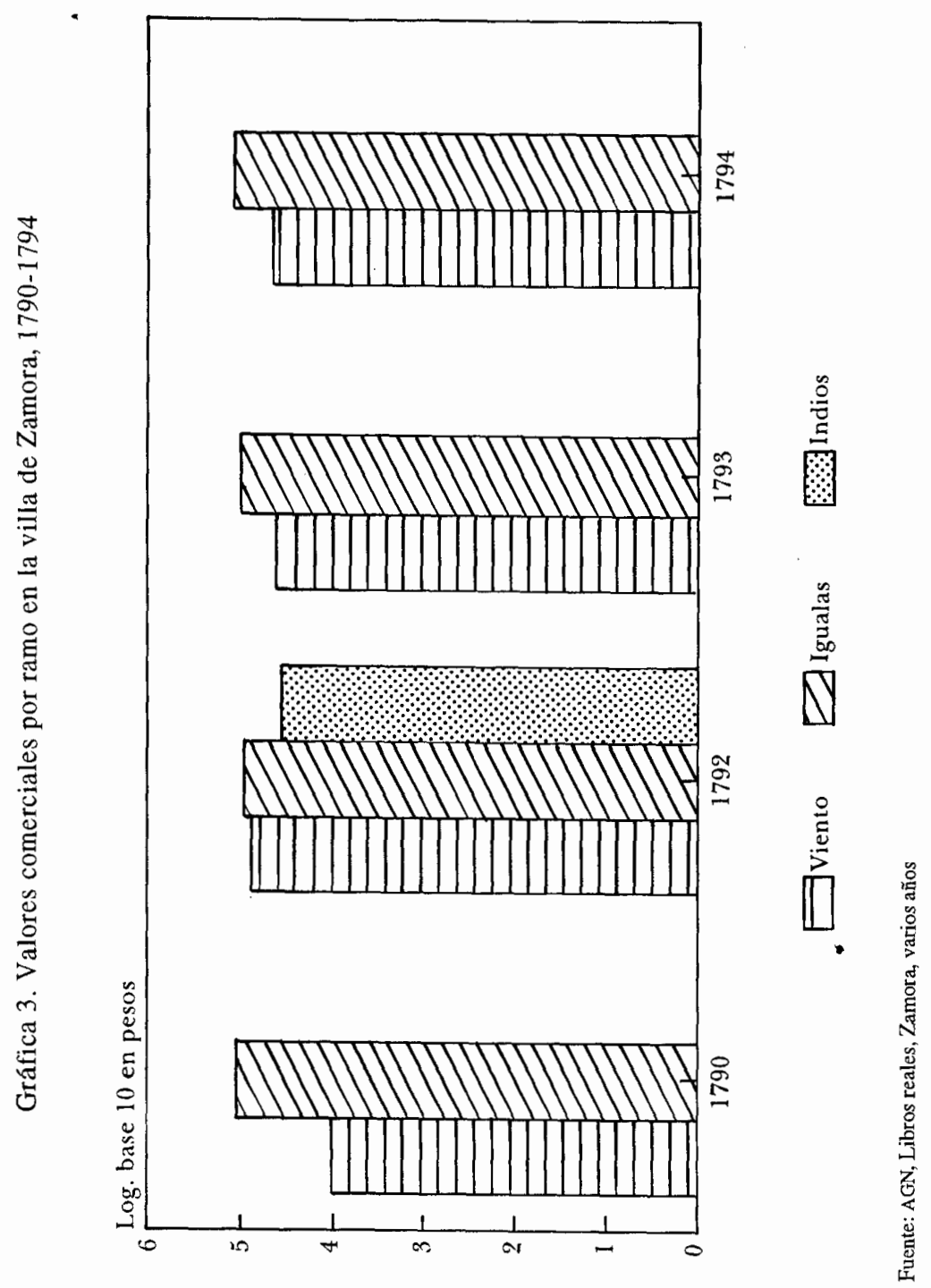


Gráfica 4. Participación indígena por valor y veces en la villa de Zamora, 1792
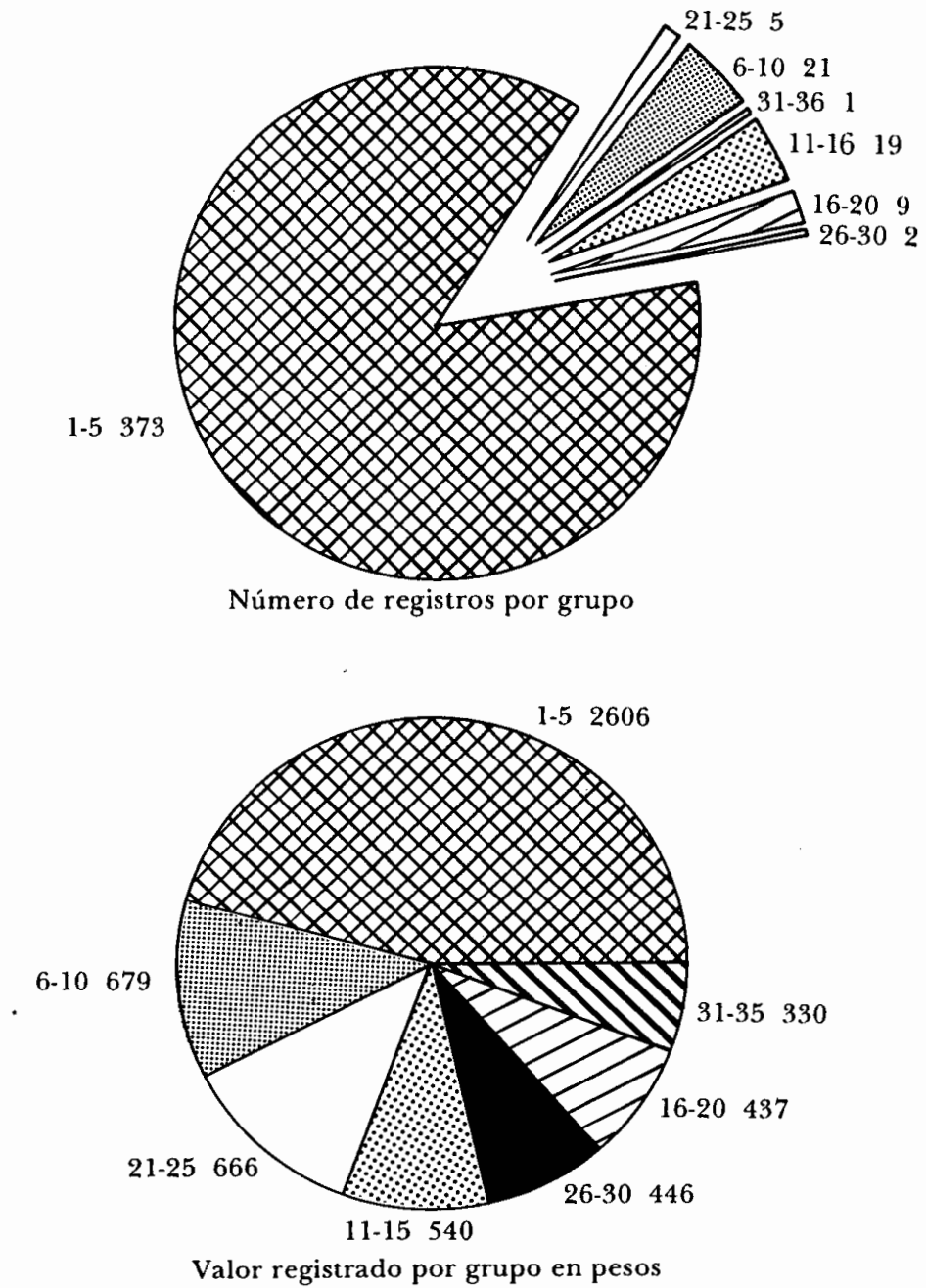

Nota: AGN, AFAPM, Zamora, Libro de indios, 1792 
Gráfica 5. Participación por valor y veces en la villa de Zamora, 1792

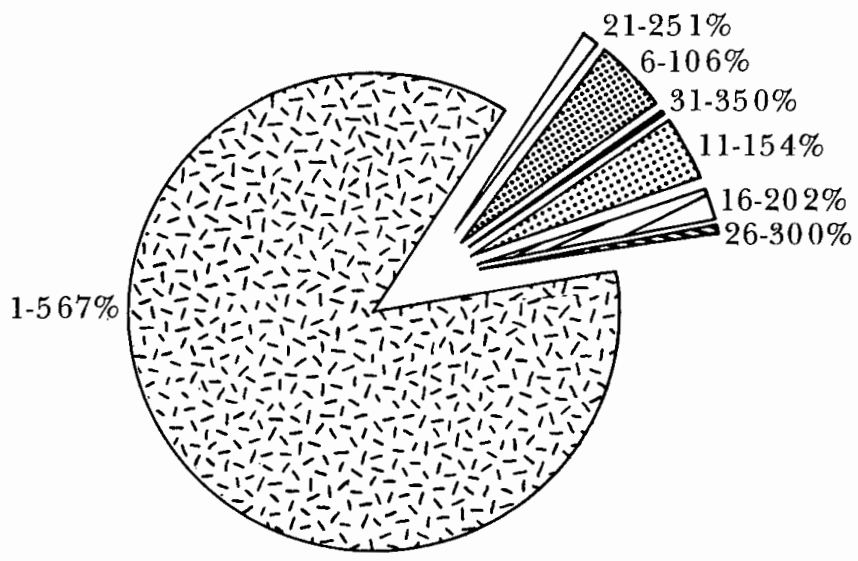

Porcentaje del número por grupo

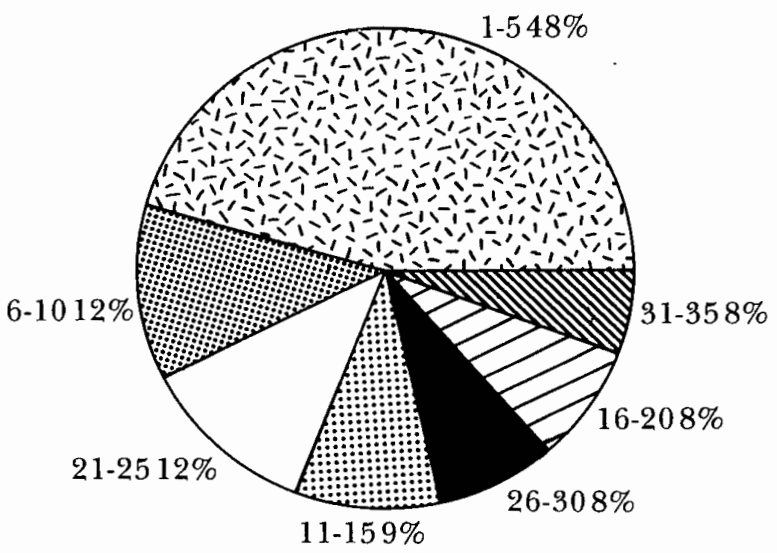

Porcentaje del valor por grupo

Fuente: AGN, AFAPM, Zamora, 1792 


\section{BIBLIOGR A FIA}

-Acuña, René, Relaciones geográficas del siglo Xvi: Michoacán, UNAM, México, 1987, vol. 9 .

-Ajofrín, Francisco de, Diario del viaje a la Nueva España, México, 1936.

-Basalenque, Diego, Historia de la provincia de San Nicolás Tolentino de Michoacán del N.P.S. Agustín, México, 1963.

-Blalock, Hubert M., Estadística Social, Fondo de Cultura Económica, México, 1986.

-Bravo Ugarte, José (introd.), Inspección ocular en Michoacán. Región central y sudoeste, Editorial Jus, México, 1960.

- Breve descripción del obispado de Michoacán (finales del siglo XVIII)", Boletín del Archivo General de la Nación, vol. XI, 1940.

-Calvo, Thomas, "Migraciones a Zamora en los albores de la independencia", Thomas Calvo y Gustavo López (coords.), $\mathrm{Mo}$ vimientos de población en el occidente de México, El Colegio de Michoacán/Centre d'Etudes Mexicaines et Centramericaines, México, 1988.

-Cardozo Galué, Germán, Michoacán en el siglo de las luces, El Colegio de México, México, 1979.

-Casillas y Cabrera, Francisco, Colección de ordenanzas para el gobierno del obispado de Michoacán, México, 1776.

-Escobar, Matías de, Americana Thebaida, vitas patrum de los religiosos hermitaños de N. P. San Agustín de la Provincia de San Nicolás Tolentino de Mechoacán, Balsal Editores, Morelia Mich., 1970 ( $1^{2}$ edición 1729).

-Florescano, Enrique e Isabel Gil, Descripciones económicas generales de Nue. va España, 1784-1817, SEP/INAH, México, 1973-1976, vols. I y II.

-Floud, Roderick, Métodos cuantitativos para historiadores, Alianza-Universidad, España, 1983.

-Fonseca, Fabián de y Carlos Urrutia,
Historia general de la Real Hacienda, Secretaría de Hacienda y Crédito Público, México, 1978.

- Garavaglia, Juan Carlos y Juan Carlos Grosso, "De Veracruz a Durango: un análisis regional de Nueva España borbónica", Siglo XIX, año II, núm. 4, 1987. , Las alcabalas novohispanas (1776-1821), Banca Cremi/Archivo General de la Nación, México, 1987.

- "Marchands, hacendados et paysans a Tepeaca. Un marché local mexicain a la fin du XviIIe siècle", Annales. Economies Sociétés Civilisations, núm. 3, mayo- junio de 1989.

-Garner, Richard L., "Exportaciones de circulante en el siglo XVIII (1750-1810)", Historia Mexicana, vol. XXXI (4), núm. 124, pp. 544-598, 1982.

, "Seminario de estadística histórica", CIESAS/Instituto Mora, agosto-diciembre de 1992.

-Gómez de Orozco, Federico, Crónicas de Michoacán, Universidad Nacional Autónoma de México, México, 1954.

-González, Luis, Zamora, El Colegio de Michoacán Consejo Nacional de Ciencia y Tecnología, México, 1984.

-Humboltd, Alejandro, Ensayo político sobre el reino de la Nueva España, Editorial Porrúa, México, 1978.

-Klein, Herbert, "La economía de la Nueva España, 1680-1809: un análisis a partir de las cajas reales", Historia Mexicana, vol. XXXIv (4), núm. 136, pp. 561609 , 1985.

-Lerner, Victoria, "Consideraciones sobre la población de la Nueva España (1793. 1810), según Humboltd y Navarro y Noriega", Historia Mexicana, vol. XVII, (3), núm. 67, pp. 327-348, 1968.

-López Sarrelangue, Delfina, "La población indígena de la Nueva España en el siglo Xvm", en Elsa Malvido y Miguel Ángel Cuenya (comps.), Demografía histórica de México, siglos XVI-XIX, Instituto de Investigaciones Dr. José Ma. Luis Mora/Universidad Autónoma Metropolitana, México, 1993. 
-López Lara, Ramón (presentación), $E l$ obispado de Michoacán en el siglo Xrm, Fimax Publicistas,Morelia, Mich., 1973 (12a edición mediados del siglo xvII).

- Martínez de Lejarza, Juan José, Análisis estadístico de Michoacán en 1822, Fimax Publicistas, Michoacán, 1974.

- Mazín Gómez, Óscar, El gran Michoacán: cuatro informes del obispado de Michoacán, 1759-1769, El Colegio de Michoacán, Zamora, 1986.

-Morin, Claude, Michoacán en la Nueva España del siglo XVIII. Crecimiento y desigualdad en una economía colonial, Fondo de Cultura Económica, México, 1979.

-Rees Jones, Ricardo, El despotismo ilustrado y los intendentes de la Nueva España, Universidad Nacional Autónoma de México, México, 1979.

-Robinson, David J., "Patrones de migración en Michoacán en el siglo XVIIr: datos y metodologías", en Thomas Calvo y Gustavo López (comps.), Movimientos de población en el occidente de México, El Colegio de Michoacán/Centre D' Etudes
Mexicaines et Centramericaines, México, 1988.

-Romero, José, Noticias para formar la historia y la estadística del obispado de Michoacán, México, 1862.

-Silva Herzog, Jesús (comp.), Documentos relativos al arrendamiento del impuesto o renta de alcabalas de la ciudad de México y distritos circundantes, Secretaría de Hacienda y Crédito Público, México, 1945, vol. Iv.

-Silva Riquer, Jorge, Las alcabalas co. mo fuente para la historia económica. La Administración Foránea de Alcabalas de Michoacán, 1777-1821, Instituto Mora, México, 1993.

-María José Gatrido, "La ciudad de Valladolid y su entorno agropecuario. Algunas formas de abasto al mercado urbano, 1793-1800", Cuadernos de historia, Siglo $X I X$ (en prensa).

-TePaske, John J., "La crisis financiera del virreinato de Nueva España a fines de la colonia", Secuencia, núm. 19, enero-abril de 1991. 


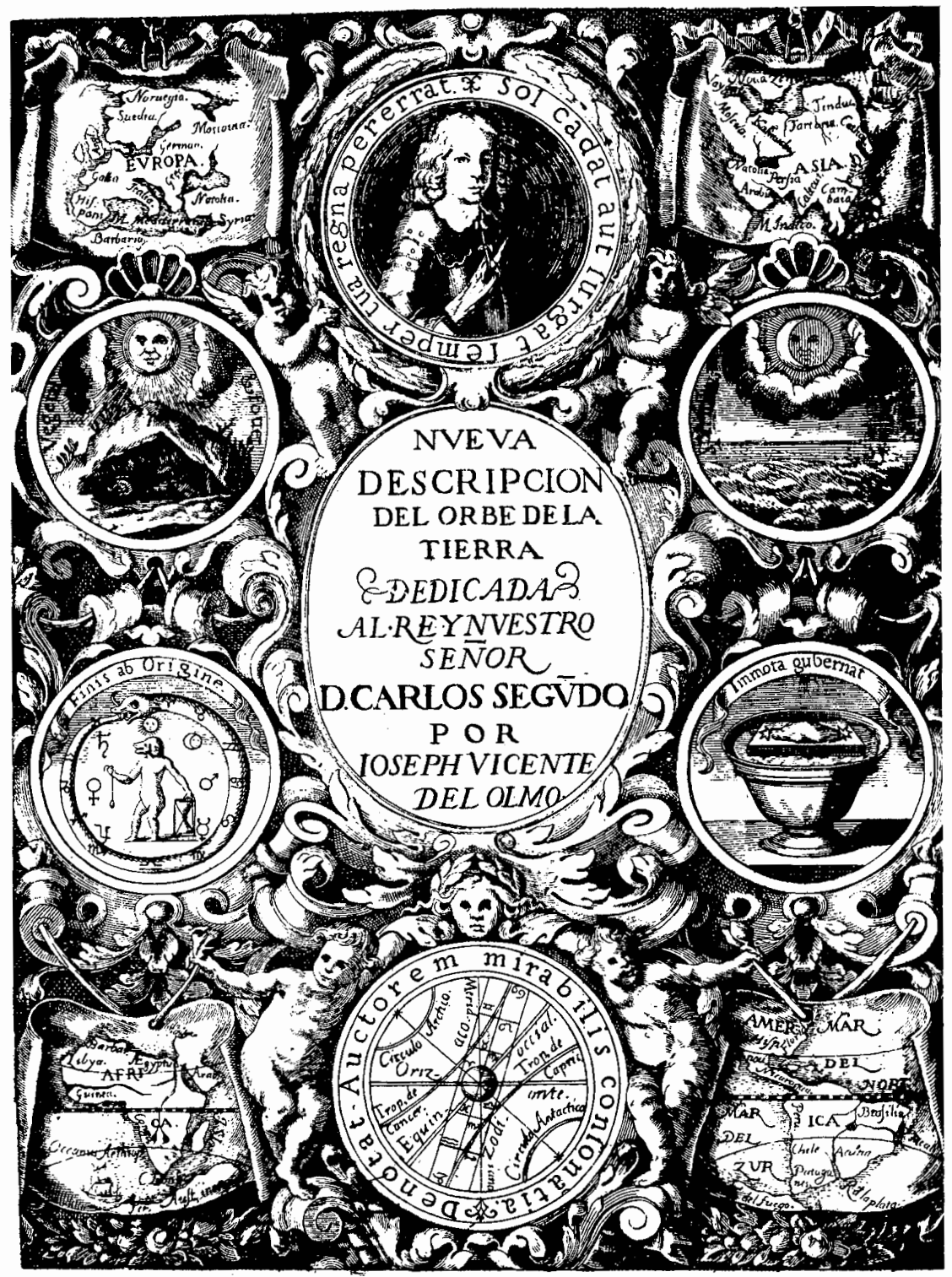

